\title{
Current research directions in 3D printing in medicine
}

\author{
"...individual 3D tissue models can be very helpful in cancer \\ research and patient-specific therapy planning and therefore \\ are rapidly developing at the moment."
}

First draft submitted: 21 December 2015; Accepted for publication: 22 December 2015; Published online: 22 January 2016

\section{Keywords: 3D printing $\bullet$ additive manufacturing $\bullet$ bioprinting $\bullet$ patient-specific implant}

3D printing for biomedical applications seems to be a technology that is developing in a wavelike manner. Not long after the first attempts for computer-aided design and manufacturing (CAD/CAM) were made in fields such as mechanical engineering and design, researchers also tried to apply these new possibilities in medicine. Only a few years later, the first patient-specific implants, for example, for the treatment of skull defects, became available.

While in the very beginning subtractive technologies such as computerized numeric controlled milling were still used, soon new options for additive manufacturing (AM) started to take off [1]. For biomedical applications, laser-based methods such as selective laser sintering (SLS) or 3D powder printing were mostly used, both of which were mostly limited in the beginning to metals and ceramic materials, respectively. A very important step therefore was the development of fused deposition modeling (FDM) as the first extrusion-based AM technology using polymeric materials. For biomedical applications, manufacturing of porous 3D scaffolds with defined outer and inner morphology and their utilization in tissue engineering was investigated in detail, using FDM of poly(lactic acid) or polycaprolactone. These polymers were also among the first biodegradable materials successfully applied in AM.

Probably because of the limitations concerning the applicable materials (most early AM machines could only be operated with a few different materials) and the high price of the devices, even at the beginning of the 21st century only a few groups further investigated AM technologies for medical applications. But the situation has changed dramatically since a variety of cheaper $3 \mathrm{D}$ printers have become available, of which many can handle different types of materials, offering the necessary flexibility for new developments. In addition, the breakthrough concerning integration of living cells in the printing process ('bioprinting') was achieved using ink-jet as well as extrusion-based technologies, opening up the possibility to directly generate artificial tissues.

We have therefore seen a strong increase of publications in the field of 3D printing in medicine in the last couple of years, coming from researchers from all over the world, accompanied by new conferences, solely focused on this topic. Nevertheless, we are still at the beginning of a huge and strong development and nobody knows what will become possible in the future.

In my opinion, the following directions are those with the strongest driving force at the moment:

- Development of new biomaterials, suitable for a variety of different AM technologies.

- Improvement of cell integration with the aim of processing cell-laden constructs of clinically relevant size.

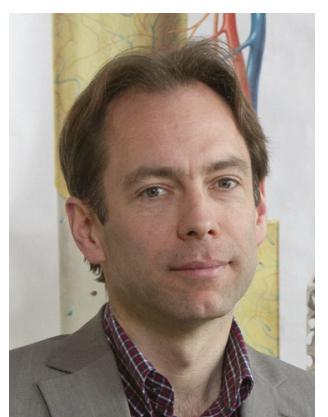

Michael Gelinsky Centre for Translational Bone, Joint \& Soft Tissue Research, Technische Universität Dresden, Fetscherstr. 74, 01307 Dresden, Germany michael.gelinsky@tu-dresden.de 
- Manufacturing of more complex constructs, comprising different materials and/or different cell types in a spatially highly controlled manner.

Industry has already provided us with improved AM machines, which often can handle a variety of different (bio)materials and which can be adjusted to different material properties and working conditions. Most extrusion-based devices are equipped with multiple dosing systems nowadays so that several materials can be applied in one scaffold. Such material combinations, and also the fact that materials are coming from different classes such as ceramics and polymers, lead to constructs with fascinating new properties or can be used to make constructs fitting to defects at anatomical interfaces, involving two or more different types of tissue [2].

Taking the three approaches mentioned above together, it will become possible not only to make a piece of cartilage, including the cells of an individual patient and fitting perfectly to a distinct defect, for example, in a joint - but to create functional tissue of complex organs such as the kidney or liver. We will certainly not be able to manufacture a whole human organ that can be transplanted into a patient in the next few decades; however, printed artificial organ models will become very important for drug screening and basic research purposes, hopefully helping to reduce the number of laboratory animals. A key issue is the development of functional blood capillary-like structures that can be used for oxygen and nutrient supply as well as mass transport. Many groups worldwide have started to work on this topic and significant progress has already been made $[3,4]$. Nevertheless, it remains a very ambitious goal to finally combine both: an artificial vascular system that is big and strong enough to be microsurgically connected to the human vasculature and sufficiently small and dendritic to act as a supply system for the cells, making up the respective tissue model.

The fast development of biomedical 3D printing meets with a global trend concerning more patientspecific, individualized therapies. One has to rec-

\section{References}

1 Chua CK, Leong KF. 3D Printing and Additive Manufacturing. Principles and Applications. World Scientific Press, Singapore (2015).

2 Luo Y, Lode A, Sonntag F, Nies B, Gelinsky M. Well-ordered biphasic calcium phosphate/alginate scaffolds fabricated by multi-channel 3D plotting under mild conditions. J. Mater. Chem B 1, 4088-4098 (2013). ognize that, for example, drugs can affect individuals very differently and that individually designed therapies could help better than standardized ones. AM offers not only the tools for the production of patient-specific implants but also for drug-eluting biomaterials that can be loaded with the respective agent during the printing process. Such agents could be beside pharmaceutics, autologous cells, bone marrow or blood components - and their inclusion in the scaffold fabrication process is called bioprinting or biofabrication. Development of novel (bio)polymer hydrogels for bioprinting purposes is one intensively investigated topic at the moment. Here we are facing the problem that the demands concerning viscosity are very different ones when looking on processability and shape fidelity on one hand and cell survival on the other [5]. As human cells do not tolerate being embedded in a stiff matrix, sufficiently high viscosity is needed to print real 3D, still open-porous constructs. Several approaches to overcome this problem have been published in the last few years, including utilization of sacrificial support materials or blending with soluble components, which provide suitable viscosity during the printing process but are dissolved after gelation and during further cell cultivation [6]. Finally, individual 3D tissue models can be very helpful in cancer research and patient-specific therapy planning and therefore are rapidly developing at the moment [7].

$3 \mathrm{D}$ printing in medicine is and will continue to be a very fascinating and fast-growing field of research and I am sure that more and more developments will find their way toward clinical application.

\section{Financial \& competing interests disclosure}

The author has no relevant affiliations or financial involvement with any organization or entity with a financial interest in or financial conflict with the subject matter or materials discussed in the manuscript. This includes employment, consultancies, honoraria, stock ownership or options, expert testimony, grants or patents received or pending, or royalties.

No writing assistance was utilized in the production of this manuscript.

3 Kolesky DB, Truby RL, Gladman AS, Busbee TA, Homan KA, Lewis JA. 3D bioprinting of vascularized, heterogeneous cellladen tissue constructs. Adv. Mater. 26, 3124-3130 (2014).

4 Miller JS, Stevens KR, Yang MT et al. Rapid casting of patterned vascular networks for perfusable engineered threedimensional tissues. Nature Mater. 11, 768-774 (2012).

5 Malda J, Visser J, Melchels FP et al. 25th anniversary article: engineering hydrogels for biofabrication. Adv. Mater. 25, 5011-5028 (2013). 
6 Schütz K, Placht AM, Paul B, Brüggemeier S, Gelinsky M, Lode A. 3D plotting of a cell-laden alginate/methylcellulose blend: towards biofabrication of tissue engineering constructs with clinically relevant dimensions. J. Tissue Eng. Regen. Med. doi:10.1002/term.2058 (2015) (Epub ahead of print).
7 Wang C, Tang Z, Zhao Y, Yao R, Li L, Sun W. Threedimensional in vitro cancer models: a short review. Biofabrication 6, e022001 (2014). 
